\title{
The Technique to Design Sharing Maintenance Resources among Maintenance Modules
}

\author{
Bo Zhang ${ }^{1, *}$, Ying $\mathrm{Xu}^{2}$, Fusheng Liu ${ }^{1}$, Shouhua Chen ${ }^{1}$ and Ying Shen ${ }^{1}$ \\ ${ }^{1}$ Department of Technical Support Engineering, Academy of Armored Force Engineering, Beijing, China \\ ${ }^{2}$ Department of Ammunition Engineering, Ordnance Engineering College, Shinjiazhuang, China \\ *Corresponding Author
}

\begin{abstract}
To promote modularized maintenance force building, the reasons to share resources among maintenance modules and the standards to design share resources are analyzed, based on the kinds of classification result of maintenance modules. The technique and process to design sharing resources are researched, whose feasibility and validity were verified by living example. The technique can improve resources using efficiency in the modularized maintenance force, reduce maintenance resources requirement.
\end{abstract}

Keywords-maintenance task; maintenance module; sharing maintenance resources; design technique

\section{INTRODUCTION}

Under the conditions of Informationization, many kinds of weapons are needed to put into integrative joint operations. There are too many kinds and quantities of maintenance tasks in integrative joint operations. Modularized maintenance force can flexibly group and quickly respond to various kinds of maintenance tasks, which can satisfy integrative joint operations' requirement ${ }^{[1 \sim 3]}$.
Maintenance module is composed of resources required by maintenance tasks. All of the resources perform tasks at the same time ${ }^{[3,4]}$. At the present, there are many documents which adopted the concept of maintenance module, but all the documents researched maintenance module as a whole ${ }^{[5-7]}$. But there are a little of maintenance resources must to perform many maintenance tasks in the maintenance process., which usually are the maintenance bottlenecks. If the resources only belong to one maintenance module, it will be result in more maintenance resources required and maintenance cost increased, even maintenance tasks delayed. Therefore, these resources need to be sharing resources among maintenance modules, which will be occupied by maintenance module when it performs maintenance task. These resources, such as high grade technician, large and costly resources, should to be sharing resources which are not belong to a certain maintenance module. It is obvious that modularized maintenance force is composed by many kinds of maintenance modules and sharing resources, showed as FIGURE I . All the documents about maintenance module did not research the problem of sharing resources ${ }^{[8-10]}$.

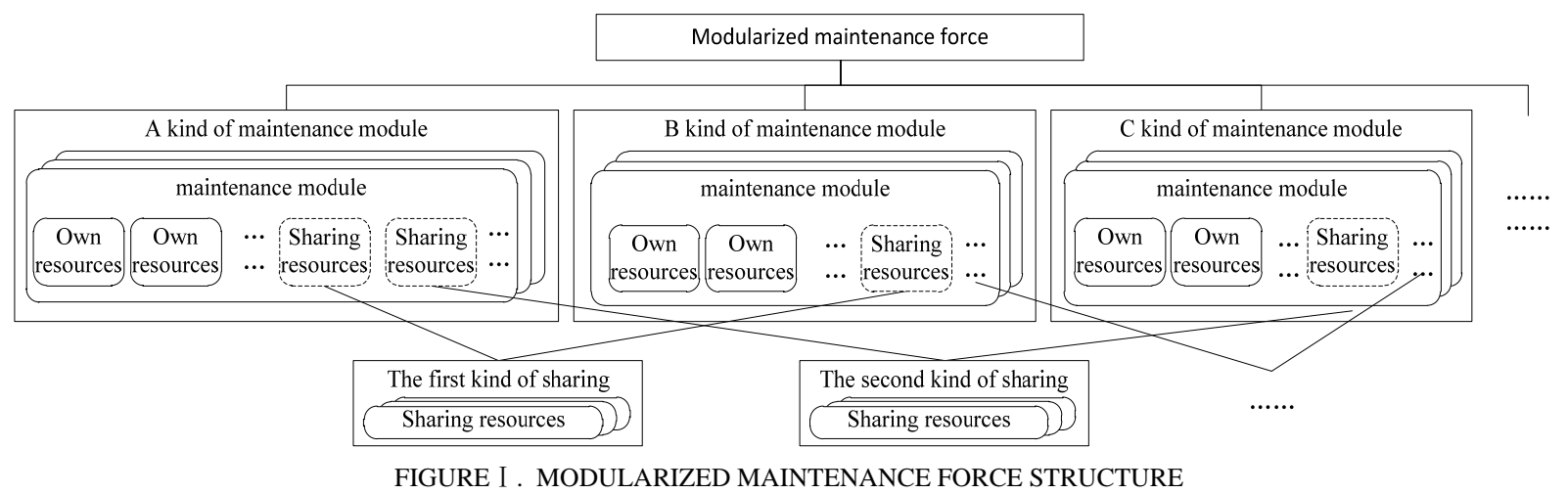

According to the resort of maintenance module kind design, which confirmed the tasks maintenance module can perform and resources composed maintenance module, the reason of maintenance modules sharing resources, the target and standard of designing sharing maintenance resources are analyzed. The technique to design sharing maintenance resources is researched, which is looked forward to providing support for accurate support and maintenance support force transformation building.

\section{The REAson of MAINTENANCE Modules SHARING RESOURCES}

Not all of maintenance resources must be shared among maintenance modules. The reason that maintenance resources are shared among maintenance modules is given as follows,

(1) Sharing maintenance resources are general resources needed by many kinds of maintenance modules to perform maintenance tasks. The resources shared among maintenance modules will result in resources using efficiency improved and lower maintenance resources requirement. 
(2) The maintenance resources should be sharing resources whose effective occupation rates are low. If the resource belongs to one kind of maintenance modules, there will be serious resources waste that results in maintenance tasks delayed and maintenance cost increase. The reason of resources waste is that all of the resources composed maintenance module perform maintenance task as a whole, which does not need the resource, but the resources is occupied. For reducing maintenance cost and enhancing maintenance ability, the resources waste should be avoided. So the resources which waste seriously should be shared among maintenance modules.

(3) The maintenance resources should be sharing resources which seriously effect maintenance tasks performing and may be the bottlenecks of maintenance process. Different resources have different characters and exert different effectiveness in maintenance process, whose waste will differently effect maintenance tasks. There is more opportunity for the kind of resources to be maintenance process bottlenecks, which are fewer and used more intensely than other kinds of resources. This kind of resources are more important for maintenance tasks than other resources. If the kind of resources just belong to one maintenance module, there will be serious resource waste which will effect maintenance task carried out favourably.

\section{The TARGET AND STANDARD OF DESIGNING SHARING MAINTENANCE RESOURCES}

The target of sharing resources among maintenance modules is to improve using efficiency of maintenance resources and reduce maintenance resources requirement on the premise that maintenance tasks are completed favourably. According to the reason of maintenance modules sharing resources, the standard of designing sharing maintenance resources is given as follow,

(1) Sharing resources must be needed by many kinds of maintenance modules to perform maintenance tasks.

(2) If the sharing resource belongs to one maintenance module, there will be more waste.

(3) Sharing resources effect maintenance tasks greater than other resources.

For farther research, some definitions are given as follow to quantify the standards above,

(1) Sharing rate. Sharing rate describes the number of maintenance module kinds which use the kind of maintenance resource.

Definition 1: the number of kinds of maintenance module kinds which need the resources to perform maintenance tasks is the kind of resources' Sharing rate.

It is obvious that sharing rate of one certain resource is an integer between 1 to $U$, which is the number of kinds of maintenance modules.

(2) Noneffective occupation resource-hours. If the resource belongs to a certain maintenance module, all of the resources composed the moledule as a whole perform maintenance tasks, but not all of the resources are necessary. The resources are occupanted but do not participate in performing tasks, which cause to resources waste, showed as FIGURE II. To quantify the resources waste, the conception of noneffective occupation resourse-hours is brought forward.

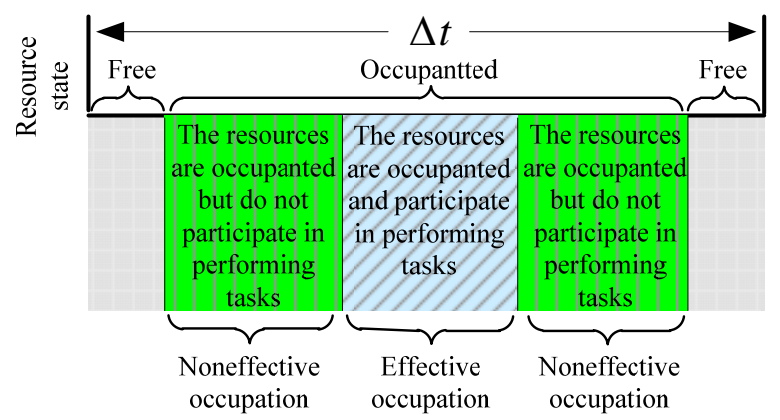

FIGURE II. SKETCH MAP OF MAINTENANCE RESOURCE NONEFFECTIVE OCCUPATION

Definition 2: If one kind of resources are one maintenance module's self possession and don't share whit other maintenance module, the margin of all of resourse-hours the kind of resources were occupied by every maintenance moduls and the effective resourse-hours the kind of resources were occupied by maintenance moduls and participated in performing tasks, is noneffective occupation resource-hours of the kind of resources.

According the definition above, maintenance resource noneffective occupation resource-hours is,

$$
\sum_{u=1}^{U} \sum_{m=1}^{M}\left(\lambda_{m} \cdot t_{m} \cdot f_{u m} \cdot s_{u k}\right)-\sum_{m=1}^{M}\left(\lambda_{m} \cdot t_{m} \cdot r_{m k}\right)
$$

Where $E_{k}$ is the noneffective occupation resource-hours of the $k$ kind of resources, $M$ is the number of kinds of maintenance tasks, $U$ is the number of kinds of maintenance modules, $\lambda_{m}$ is the average velocity that all of maintenance tasks arrive, $t_{m}$ is the average velocity that $m$ kind of maintenance tasks arrive. If the $u$ kind of maintenance modules can perform the $k$ kind of maintenance tasks, $f_{u m}=1$, otherwise $f_{u m}=1$; $s_{u k}$ is the number of the $k$ kind of resources composed the $u$ kind of maintenance modules, $r_{m k}$ is the number of the $k$ kind of resources required by the $k$ kind of maintenance tasks.

(3) Importance degree. A kind of resources' importance degree to maintenance tasks is influenced by the number and using intensity of the kind of resources. The using intensity of the kind of resources is the workload which the kind of maintenance resources can afford in certain time,

$$
I_{k}^{\prime} \sum_{m=1}^{M} \lambda_{m} \cdot t_{m} \cdot r_{m k}
$$

Where $I_{k}^{\prime}$ is using intensity of the $k$ kind of resources.

Usually, there are less valuable and exiguous maintenance resources than other resource which are the bottlenecks of 
maintenance process. The experiencer the kind of resources are, the less the kind of resources equipped. So the reason of resources equipped less can be simply summed up as high prise of the resources.

According to the analysis above, the more intensely resources be used and the higher prise of the resource is, the higher the importance degree of the resource is. Based on these, the definition of importance degre is given as follow,

Definition 3 : The product of relative cost and relative using intensity of one kind of resources is the kind of resources' importance degree.

A kind of resources's relative cost is the ratio of the cost of the kind of resource and the highest cost of resources; a kind of resources's relative using intensity is the ratio of the using intensity of the kind of resource and the highest using intensity of resources. According these, the resource's importance degree can be calculated as fllow,

$$
I_{k} \frac{I_{k}^{\prime}}{\max _{k \in[1, N]}\left(I_{k}^{\prime}\right)} \cdot \frac{C_{k}}{\max _{k \in[1, N]}\left(C_{k}\right)}
$$

Where $N$ is the number of kinds of resources, $c_{k}$ is the single cost of the $k$ kind of resources, $I_{k}$ is the importance degree of kinds of resources.

(4) Waste quotiety. Different kind of resources' noneffective occupation resource-hours affect maintenance tasks differently, whose sharing rates are higher than 1 . To scale the influence of resources' importance degree and noneffective occupation resource-hours, the definition of waste quotiety is given as follow,

Definition 4: the product of resources' importance and noneffective occupation resource-hours is called resources' waste quotiety.

According to the definition of waste quotiety, the resource's waste quotiety can be calculated as fllow,

$$
U_{k} I_{k} \cdot E_{k}
$$

Where $U_{k}$ is the waste quotiety of the $k$ kind of resources.

The higher importance degree, the more noneffective occupation resource-hours and the higher waste quotiety of a kind of resources, the more influence the kind of resources affect to maintenance tasks. To ensure maintenance tasks performed successfully, the waste quotiety of all of resources should keep at low level and the kind of resources should to be shared among maintenance modules whose waste quotiety is high.

\section{The Technique to Design Sharing MaInTENANCE RESOURCES}

According to analysis above, the process of designing sharing maintenance resources is given as FIGURE III.

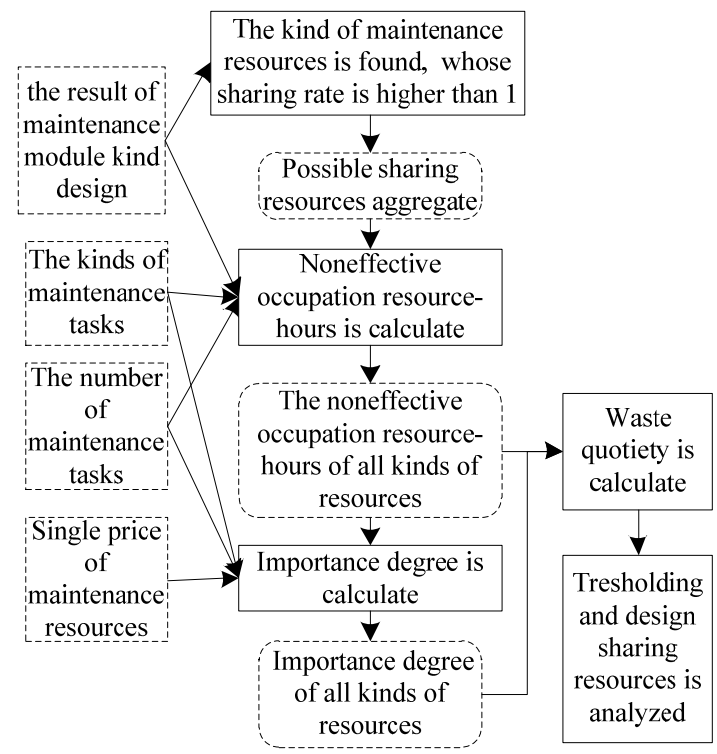

FIGURE III. THE PROCESS OF DESIGNING SHARING MAINTENANCE RESOURCE

The process of of designing maintenance sharing resource showed as FIGURE III is composed by steps follow,

Step 1: possible sharing resources aggregate is found. To find possible sharing resources aggregate, according to the result of maintenance module kind design, the sharing rate of every kinds of resources are calculated and the kinds of resource are found whose sharing rate is higher than 1.

Step 2: the noneffective occupation resource-hours of all kinds of maintenance resources is calculated as Eq (1).

Step 3: the importance degree of all kinds of maintenance resources is calculated as Eq (2), (3).

Step 4: the waste quotiety of all kinds of maintenance resources is calculated as Eq (4).

Step 5: according to the resource' kinds, the reasonable treshold of waste quotiety by consulting correlative expert. The kind of resources should to be sharing resources whose waste quotiety is higher than tresholding.

\section{LIVING EXAMPLE}

The feasibility and validity of the technique given above is proved through an living example of a certain type of equipment. The type of equipment is composed by fire system, radar system, chassis system and fire control system, which is an representative compositive equipment composed by many different function system. A certain level maintenance force of the type of equipment is in change of 50 kiinds of maintenance tasks of the type of equipment, in which there are fire system maintenance modules, radar system maintenance modules, 
chassis system maintenance modules and fire control system maintenance modules. The function of all kinds of maintenance equipments (the kinds of maintenance tasks which a kind of maintenance modules can performed) is showed as TABLE I and the resources composed of all kinds of maintenance equipments is showed as Table II.

TABLE I. THE FUNCTION OF ALL KINDS OF MAINTENANCE EQUIPMENTS

\begin{tabular}{|c|c|c|c|}
\hline $\begin{array}{c}\text { The } \\
\text { kinds of } \\
\text { maintena } \\
\text { nce } \\
\text { moduls }\end{array}$ & $\begin{array}{c}\text { the kinds of } \\
\text { maintenance tasks } \\
\text { which a kind of } \\
\text { maintenance modules } \\
\text { can performed }\end{array}$ & $\begin{array}{c}\text { The } \\
\text { kinds of } \\
\text { mainten } \\
\text { ance } \\
\text { moduls }\end{array}$ & $\begin{array}{c}\text { the kinds of } \\
\text { maintenance tasks } \\
\text { which a kind of } \\
\text { maintenance modules } \\
\text { can performed }\end{array}$ \\
\hline (1) & $\begin{array}{c}1,2,3,4,5,6,7,8,9,10,18,1 \\
9,20,21,22\end{array}$ & (2) & $\begin{array}{c}11,12,13,14,15,16,17,23, \\
24,25\end{array}$ \\
\hline (3) & $\begin{array}{c}26,27,28,29,30,31,32,33 \\
, 34,35,36,37,38,39,40,4 \\
1\end{array}$ & (4) & $\begin{array}{c}42,43,44,45,46,47,48,49, \\
50\end{array}$ \\
\hline
\end{tabular}

TABLE II. THE RESOURCES COMPOSED OF ALL KINDS OF MAINTENANCE EQUIPMENTS

\begin{tabular}{|c|c|c|c|c|c|c|c|c|c|c|c|c|c|c|c|c|c|c|c|c|c|}
\hline \multirow{2}{*}{$\begin{array}{c}\text { The kinds of } \\
\text { maintenance } \\
\text { moduls }\end{array}$} & \multicolumn{21}{|c|}{ The kinds of maintenance resources } \\
\hline & A & B & C & $\mathrm{D}$ & $\mathrm{E}$ & $\mathrm{F}$ & G & $\mathrm{H}$ & I & $\mathrm{J}$ & $\mathrm{K}$ & $\mathrm{L}$ & $\mathrm{M}$ & $\mathrm{N}$ & $\mathrm{O}$ & $\mathrm{P}$ & $\mathrm{Q}$ & $\mathrm{R}$ & $S$ & $\mathrm{~T}$ & $\mathrm{U}$ \\
\hline (1) & & & & & & & & & & & & & 1 & & & & & & & 1 & 1 \\
\hline (2) & & & & & & & & & 1 & & 1 & 1 & 1 & 1 & 1 & 1 & 1 & 1 & 1 & & \\
\hline (3) & 1 & 1 & 1 & 1 & 1 & 1 & & & 1 & & & & & & & & & & & & \\
\hline (4) & & 1 & & & & & 1 & 1 & & 1 & 1 & & & & & & & & & & \\
\hline \begin{tabular}{|c|} 
Cost/ten \\
thousand yuan
\end{tabular} & 0.05 & 10 & 0.1 & 0. & 0.02 & 0.2 & 0.1 & 0.02 & 0.08 & 0.2 & 0.01 & 0.5 & 0.3 & 0.4 & 0.01 & 0.1 & 0.5 & 0.6 & 1 & 0.4 & 2 \\
\hline
\end{tabular}

Annotation: there are some main kinds of resources in Table II, other kinds of resources such as wrench, pinchers, screwdriver and so on not important are not listed.

TABLE III. BASAL CONDITION OF MAINTENANCE TASKS

\begin{tabular}{|c|c|c|c|c|c|c|c|c|c|c|c|c|c|c|c|c|c|c|c|c|c|c|c|}
\hline Serial number & \begin{tabular}{|c|} 
Tasks \\
arrival rates
\end{tabular} & Service & \multicolumn{21}{|c|}{ The kinds of resources } \\
\hline 1 & 0.085 & 0.5 & A & B & $\mathrm{C}$ & $\mathrm{D}$ & $\mathrm{E}$ & $\mathrm{F}$ & G & $\mathrm{H}$ & I & $\mathrm{J}$ & $\mathrm{K}$ & $\mathrm{L}$ & M & $\mathrm{N}$ & $\mathrm{O}$ & $\mathrm{P}$ & Q & $\mathrm{R}$ & $S$ & $\mathrm{~T}$ & $\mathrm{U}$ \\
\hline 12 & 0.075 & 1 & & & & & & & & & & & & 1 & 1 & & & & & & & & \\
\hline 13 & 0.08 & 1.5 & & & & & & & & & 1 & & & & 1 & & & & & & & & \\
\hline 14 & 0.125 & 3.5 & & & & & & & & & & & & & 1 & 1 & & & & & & & \\
\hline 15 & 0.1 & 0.5 & & & & & & & & & & & 1 & & 1 & & & & 1 & & & & \\
\hline 16 & 0.1 & 0.5 & & & & & & & & & & & 1 & & 1 & & 1 & 1 & & & & & \\
\hline 17 & 0.1 & 1 & & & & & & & & & & & & & & & & & & 1 & 1 & & \\
\hline 23 & 0.1 & 2 & & & & & & & & & & & & & 1 & & & & & & & 1 & 1 \\
\hline 27 & 0.1 & 0.5 & 1 & 1 & & & & 1 & & & & & & & & & & & & & & & \\
\hline 28 & 0.095 & 0.5 & 1 & 1 & & & & 1 & & & & & & & & & & & & & & & \\
\hline 29 & 0.1 & 1.5 & 1 & 1 & & 1 & 1 & 1 & & & & & & & & & & & & & & & \\
\hline 30 & 0.07 & 2 & & 1 & 1 & & & 1 & & & & & & & & & & & & & & & \\
\hline 34 & 0.09 & 1.5 & & & 1 & & & 1 & & & 1 & & & & & & & & & & & & \\
\hline 46 & 0.1 & 3.5 & & 1 & & & & & 1 & & & 1 & & & & & & & & & & & \\
\hline 47 & 0.115 & 1.1 & & 1 & & & & & & 1 & & & & & & & & & & & & & \\
\hline 48 & 0.1 & 1 & & & & & & & & & & & 1 & & & & & & & & & & \\
\hline
\end{tabular}

Step 1: possible sharing resources aggregate is found. It can be gotten from Table II that there are only four kinds of resources in the sharing resources aggregate, whose sharing rate are higher than 1 . The next steps can just analyze the four kinds of resources. The basal condition of maintenance tasks related to the four kinds of resources is listed in Table III.
Step 2: the noneffective occupation resource-hours of all kinds of maintenance resources is calculated as Eq (1),

$$
E_{\mathrm{B}}=2.3065, E_{\mathrm{I}}=3.16, E_{\mathrm{K}}=3.015, E_{\mathrm{M}}=1.912
$$

Step 3: the importance degree of all kinds of maintenance resources is calculated as Eq (2), Eq (3), 


$$
I_{\mathrm{B}}=1, I_{\mathrm{I}}=0.000874, I_{\mathrm{K}}=0.00058, I_{\mathrm{M}}=0.0278
$$

Step 4: the waste quotiety of all kinds of maintenance resources is calculated as $\mathrm{Eq}(4)$,

$$
U_{\mathrm{B}}=2.3065, U_{\mathrm{I}}=0.00277, U_{\mathrm{K}}=0.00176, U_{\mathrm{M}}=0.0532
$$

Step 5: by consulting correlative expert, the kind of resources should to be sharing resources whose waste quotiety is higher than 1 . So the B kind of resources should to be sharing among (3) and (4) kinds of maintenance modules.

The B kind of resources is good-sized disassembly and assembly machine, which is shared in real maintenance process. It shows that the technique is feasible and the result matches practical case.

\section{CONCLUSION}

Modularized maintenance force is one direction of maintenance force transformational development. But there was no research about sharing resources. Base on deeply analyzing the reason of maintenance modules sharing resources, the target and standard of designing sharing maintenance resources are brought forward. The technique and progress to design sharing maintenance resources are given whose feasibility and applicability are proved by living example. The technique and progress can effectively improve maintenance resources using efficiency and maintenance efficiency, provide technical support for modularized maintenance force transformational development; it can also provide technical reference to solve bottleneck problem in group technology.

\section{REFERNCES}

[1] Major Charlie Ward. Managing ARFORGEN operations in a modular sustainment brigade [J]. Army Sustainment, 2010,42(1):2-4.

[2] Congressional Research Service, Washington, DC. U.S. Army's Modular Redesign: Issues for Congress. CRS Report for Congress (ADA436231/XAB) .2006.2.6

[3] YE Zhanwu. Research on the Unit Organization and Arrangement Modes of Equipment Maintenance Support[D], Shijiazhuang: Ordnance Engineering College, 2005.

[4] TBB 400-2008. Man hours and minimum manpower unit of ordnance equipment maintenance.

[5] ZHAO Wukui. Equipment support studies[M]. Beijing: Chinese People's Liberation Army Publishing House. 2003.

[6] ZHANG Jianjun, LIU Fang, ZHANG Tao, GUO Bo. The Model of Combat Unit Spares Availability Base on BCMP Queuing Network[J]. Acta Armamentarii, 2009, 30 (1): 110-113.

[7] QU Changzheng, YU Yongli. Equipment Maintenance Support System Performance Analysis Based on Stochastic Petri Net[J]. Systems Engineering-Theory\&Practice, 2012, 32 (11): 2512-2516.

[8] ZHANG Bo, XU Ying, ZHAN Zeying. Research on Method of Designing Composition of Maintenance Modules for Antiaircraft Missile system[J]. Aerodynamic Missile Jour, 2012, (3): 73-76.

[9] ZHANG Bo, YU Yongli, XU Ying, QU Changzheng, ZHANG Liu. The Method to Analyze Maintenance Resources Requirement Based on Queueing Theory[J]. Journal of Ordnance Engineering College, 2011, 23(5): 10-13.

[10] SUN Wenxuan, YANG Hongwei, YANG Xueqiang. Optimization Research on the Human Resources of Basic Support Unit Based on Multiobjective Constrain[J]. Journal of Academy of Armored Force Engineering, 2011, 25(3): 24-29. 